\section{R.E. Harte}

In Summer 1978, Question 4 of the Second Arts Matrix Theory paper at U.C.C. begins as follows:

"Explain what it means for a finite subset of a real vector space to be linearly independent. If $\left\{x_{1}, x_{2}, x_{3}\right\}$ is linearly independent and $t$ is real, show that

A $\left\{x_{1}-t x_{2}, x_{2}-t x_{3}, x_{3}-t x_{2}\right\}$ linearly independent $\Longleftrightarrow t \neq 1$ ".

The embarrassing fact is that the solution is wrong, but in a rather subtle way. In fact provided the three vectors $x_{1}, x_{2}$ and $x_{3}$ are distinct from one another, the statement (A) is correct, as can be and was verified by Second Year Arts students. Suppose however

$$
\text { B }
$$$$
x_{1} \neq x_{2} \neq x_{3}
$$

still assuming that the set $\left(x_{1}, x_{2}, x_{3}\right\}=\left\{x_{1}, x_{2}\right\}$ is linearly independent, then:

\section{$c\left(x_{1}-t x_{2}, x_{2}-t x_{3}, x_{3}-t x_{1}\right\}$ linearly independent} $\Leftrightarrow t=0$.

Finally if $x_{1}=x_{2}=x_{3} \neq 0$ then the statement (A) is again valid.

MORAL: linear independence should be defined for sequences, not sets.

Mathematics Department.

university College.

Conk.

\section{COMPUTER SCIENCE AND THE MATHEMATICS CURRICULUM}

\section{Anthony Karel Seda}

"As soon as an Analytical Engine exists, it will necessarily guide the future exists, science. Whenever any result is soure course of the aid, the question will thent is sought by its of calculation cen these resise - By what course by the machine in these resuls be arrived at

Charles Babbage, I 864 .

\section{\$1. Introduction} In any discussion of computer science and its relation-
ship with mathematics, from an obvious questions come to the fore.

(1) What is the rol ation?

(2) What is the role of computer science in ation?

(3) What is, or has been, the response of mathenaticians to computer science in relation to the mathematicians to U1 Um?

There are two

questions can be contemplated, at least, from which these scientist engaged in teaching. One is thot of the computer itution peering over the rampartsat in a third level instThe other, which is ours, is that at the mathematicians. arly engaged in teaching/research of the mathematician similcomputer scientists. Having thus and similarly peering at the and for reasons of space. I wish doclerso my wantage point, tion 1 , and only to touch on owestions concentrate here on ouesI wist bo bring to the attention of 
the discussion contained in the articles [4] and [5] of Professor Anthony Ralston. Ralston's conclusion is,

"It is "time to consider (i.e., try)

an alternative to the standard

undergraduate mathematics curriculum

which would give discrete analysis an

equivalent role to that now played

by calculus in the first two years

of the undergraduate curriculum".

isted the topics which Ralston proposes in orde to achieve his aim. Actually, [4] is a detailed version (83 of the argument here.

In the quotation above, Babbage is of course talking ingut algorithms, and algorithms in the words of Knuth [3], are "... really the central of the subject (computer science), "... really the central core of the subject (comester and unifies the diffthe common denominator which underlies and unifies the different branches". Indeed, Knuth has, just prior to uriting this, chosen to describe computer science as "the study of algorithms". Now, as confirmed by Knuth, the study of algor ithms is very mathematical and it is worth stating this fact in order to dispose of the short, negative reply to Question which just might be proposed from the other vantage point! Further confirmation of this fact, i.e. Of the mathematical nature of computer science, can be gained by consulting the list of topics in Section 68 of the 1980 Subject classification of Mathematical Reviews, or by actual

\section{Some History and Some Educational Philosophy}

Whilst our main discussion centres on Question 1 , it will out of place to devote a few words to Questions 2 and 3 .

One might wonder why it is today that there is a division between computer scientists and mathematicians, and that there is not more sympathy shown by each for the other's subject. After all, computer science grew out of mathematics and in its early days, some twenty five-thirty years ago, it was necessarily closely bound to mathematics. However, today, digital computers vastly predominate over analogue computers and digital computers are essentially discrete. What, though, is being taught in most mathematics departments? I suspect that it is largely either continuous mathematics, such as analysis, or relatively abstract mathenatics, to the great exclusion of discrete mathematics. Certainly this is true in U.C.C., but may be less so in non-university departments. Indeed, Ralston [4] aroues that in American universities the present-day structure of the mathematics curriculum (mainly calculus/linear algebra - at least in the first two years) has come about for reasons more to do with history and inertia (human) than with a judicious shoice of topics to meet the educational requirements of those students other than majors in physicalscience and enginee:ing.

As far as Question 3 is concerned, there are at least three discernible responses: .

(a) Ignore the oroblem - maybe it will go away.

(b) Continue teaching traditional material but illuminate it with examples/projects worked on the computer.

(c) Meet the problem head-on and design/update courses to more neariy meet the needs of those students studying computer science.

Response (a) needs no comment: ( 0 ) is outside the scope and limits of this note but surely has a lot of merit. see [2] and its references for some experiments, and also elsewhere in this Newseter; (c) is the main topic of this discussion. see $\$ 3$

Before leaving this section, there is anothe: aspect worth noting. Mathematics courses are widely helo to be 
educational, irrespective of their content, for purposes of training the mind. Can the same be said of computer science? This touches on Question 2 , because the solution Ralston has in mind for (c) is best framed in terms of a mathematical sciences degree programme and, naturally, the educational value of such a programme, over and above its content, has to be considered. Ta quote G.E. Farsythe, see [3], "The most valuable acquisitions in a scientific or technical education are the general-purpose mental tools which remain serviceable for a lifetime. I rate natural language and mathematics as the most important of these tools, and computer science as a third". Some of Knuth's own views on this can also be found in [3].

\section{Ralston's Proposals far the Mathematics Curriculum}

I want, now, to list the topics which Ralston believes could form a suitable basis for the discrete camponent in a better balanced curriculum fo: nathematics students, computer science students and others. The headings below are taken from [4] and [5] and the topies from [4].

i) Algorithms and their Analysis. Topics: the notion of an algorithm; notation for expressing algorithms; basic analysis of algorithms.

ii) Introductory Mathematical Logic. Topics: the notion of mathematical proof: the propositional calculus; Boolean algebra; the notation of the predicate calculus; introduction to the verification of algorithms.

iii) Limits and Summation. Topics: the notion of infinite processes; ideas of convergence and limits; limits of discrete functions; summation.

iv) Mathematical Induction. Topics: the principles of induction: examples of induction proofs.

v) The Oiscrete Number System. Topics: real numbers and finite number systems; definition and laws of the discrete number system; number bases other than 10 . vi) Qasic Combinatorial Analysis.

theorem and Stiriting numbers. Topics: the binomial ions; simple combinatorials; permutations and combinat -

aloorithms.

recurrence relations: ind Generatino Functions. Topics: their solution: generating dufference equations and

rating functions.

probability distribu. Topics: basic laws; discrete queueino theory;

ix) Graphs and theorems of graoh theoics: basic definitions and tree enumeration and oi : oath and colouring problems:

x)

definitions; recursive alooritheory. Todics: basic regular sets and expressions; finitecursive functions; languages and grammars: Turing finite state machines;

In connection with this list, the following shouid be noted:

(A) These topics are onlv suggestions. assumed by Ralston that they will bens. Moreover, it is ination with abstract aipebra wil be presented in some comofor in [4] it is observed that "... of computer science uhere cal "... there are numerous areas Moreover, a better balanced curriouiums an important role..." but not a complete reversal in favour of being argued far, (3) These tojics are. in viii), mathematics subjects ang as ouch exceotion of some mathematicians.

(c) Jue to the diffeiences bet here and in America, certain adjitions the educational systems need to be made were these proposals and subtractions might our context (Probably extra noresals to be adapted to fit into computability theory of computationanced material such as more 
(0) These proposals are at least worthy of consideration, for Professor Ralston has wide experience in both computer science and mathematics and backs up his suggestions with an exhaustive study.

More questions are asked here than are answered. For example, çonsideration needs to be given to the feasibility of such topics for various types of student, ranging from students of management through to honours. mathematics students. But space permits no more comment, and for answers to such questions the reader must either consult [4] and [5] or, if Ralston [5] page 484 is correct, undertake experiment for himself or herself.

Educational problems are not usually very well defined; they are likely to be controversial and to raise temperatures. Indeed it may be that Ralston's criticism does not apoly here and that all is well. If not, and this article creates some discussion of starts people thinking about the problems raised here; then it will have achieved its purpose. We hardly need reminding in 1983 that computer science is a major undergradvate subject. But what has perhaps not been widely recognised yet is the fact that the next generation of students will be taught computer science in secondary schools by those currently studying it at third-level. Future incoming students may therefore elect to study computer science "because it is familiar" just as many do now, I suspect, in the case of mathematics.

\section{References}

[1]. E.W. Dijkstra, Programming as a Discipline of Mathematical Nature, Amer. Math. Monthly, 81 (1974), 608-612.

[2]. S.P. Gordon, A Discrete Approach to Computer Oriented Calculus, Amer. Math. Monthly, 86 (1979), 385-391.
[3]. D.E. Knuth, Computer Sclence and its Relation to Mati-
ematics, Amer. Math. Monthly, $81(1974)$, $323-343$.

[4]. A. Ralston, Computer Undergraduate Curricula Science, Mathematics and the Department of Computer Underoraduat Computer Science, Mathematics and the 88 (1981), 472-485. Math. Monthly,

Department of Mathematics. University Coclege.

Cork.

\section{USING MICROCOMPUTEPS}

\section{A.W. Wickstead}

Until the last few years, most atte

computers in the teaching years, most attempts to involve at the terminal of a large computer and atting a student the whole teaching process by fresentin attempting to perform then tested. Apart from being very linited intion which was taught in this way, such orojects very limited in what could be ensive. They involve relatively have tended to be very expminals to them and a lot of (expensive computers, many terAll of this expenditure has to be ine programming effort. nique can be tried, so its use be incurred before the tech. limited.

The advent of chear microconouters in recent vears has enabled the less well financed university in recent veass has ment to acquire a computer and teaching. With such limited resources (and its use in assistance) it would be foolish to hop tand no propramming 